\title{
Local gastric RAAS inhibition improves gastric microvascular perfusion in dogs
}

\author{
Richard Truse', Fabian Voß1', Anna Herminghaus'1, Jan Schulz', Andreas P M Weber², Tabea Mettler-Altmann², \\ Inge Bauer ${ }^{1}$, Olaf Picker $^{1}$ and Christian Vollmer ${ }^{1}$ \\ 1Department of Anesthesiology, Duesseldorf University Hospital, Duesseldorf, Germany \\ 2Institute of Plant Biochemistry, Cluster of Excellence on Plant Sciences (CEPLAS), Heinrich-Heine-University Duesseldorf, Duesseldorf, Germany
}

Correspondence should be addressed to R Truse: Richard.Truse@med.uni-duesseldorf.de

\begin{abstract}
During circulatory shock, gastrointestinal microcirculation is impaired, especially via activation of the renin-angiotensin-aldosterone system. Therefore, inhibition of the renin-angiotensin-aldosterone system might be beneficial in maintaining splanchnic microcirculation. The aim of this study was to analyze whether locally applied losartan influences gastric mucosal perfusion ( $\mu$ flow, $\mu$ velo) and oxygenation $\left(\mu \mathrm{HbO}_{2}\right)$ without systemic hemodynamic changes. In repetitive experiments six anesthetized dogs received $30 \mathrm{mg}$ losartan topically on the oral and gastric mucosa during normovolemia and hemorrhage ( $-20 \%$ blood volume). Microcirculatory variables were measured with reflectance spectrometry, laser Doppler flowmetry and incident dark field imaging. Transpulmonary thermodilution and pulse contour analysis were used to measure systemic hemodynamic variables. Gastric barrier function was assessed via differential absorption of inert sugars. During normovolemia, losartan increased gastric $\mu$ flow from $99 \pm 6$ aU to $147 \pm 17$ aU and $\mu$ velo from $17 \pm 1$ aU to $19 \pm 1$ aU. During hemorrhage, losartan did not improve $\mu$ flow. $\mu$ velo decreased from $17 \pm 1$ aU to $14 \pm 1 \mathrm{aU}$ in the control group. Application of losartan did not significantly alter $\mu v e l o$ $(16 \pm 1 \mathrm{aU})$ compared to the control group and to baseline levels (17 $\pm 1 \mathrm{aU})$. No effects of topical losartan on macrohemodynamic variables or microcirculatory oxygenation were detected. Gastric microcirculatory perfusion is at least partly regulated by local angiotensin receptors. Topical application of losartan improves local perfusion via vasodilation without significant effects on systemic hemodynamics. During mild hemorrhage losartan had minor effects on regional perfusion, probably because of a pronounced upstream vasoconstriction.
\end{abstract}

\section{Introduction}

Adequate splanchnic perfusion and oxygenation is vital to maintain the intestinal mucosal barrier function. During circulatory shock the microcirculatory perfusion is critically impaired, resulting in oxygen extraction deficit and regional ischemia. Concerning gastrointestinal microcirculation, this leads to impaired barrier function and has been shown to enable translocation of bacteria and toxins from the intraluminal to the intravascular compartment (Deitch et al. 2004). In shock, circulating blood volume is redistributed in favor of more vital organs at the expense of the gut (Jakob \& Takala 2000). In contrast to sepsis, circulatory shock causes splanchnic 
hypoperfusion with no initial change in splanchnic oxygen consumption (Ackland et al. 2000). Procedures that recruit the gastrointestinal microcirculation, thereby counteracting the splanchnic vasoconstriction, may improve regional organ function. Splanchnic circulation is impaired early in development of hypoperfusion, but shows a delayed recovery beyond restoration of normal systemic hemodynamic variables (Price et al. 1966).

The renin-angiotensin-aldosterone system (RAAS) plays a major role in regulating blood pressure and vascular response to injury (Kurz \& Zehr 1978). In particular renin via angiotensin reduces mesenteric perfusion due to high affinity and expression of the angiotensin receptor in the splanchnic region (Gunther et al. 1980) and increased regional angiotensin production (Yilmaz et al. 1999). In this context, the RAAS plays a more important role than the sympathetic-mediated mesenteric vasoconstriction following major trauma. Splanchnic hypoperfusion is not consistently abolished by sympathetic ablation via thoracic epidural anesthesia (Väisänen et al. 1998, Meissner et al. 1999, Siniscalchi et al. 2015), whereas pharmacologic RAAS inhibition or nephrectomy blunted mesenteric vasoconstriction (Bailey et al. 1987, Aneman et al. 2000). Especially angiotensin 2 is believed to play a crucial role in mediating splanchnic vasoconstriction in hemorrhagic shock (Ceppa et al. 2003). Angiotensin 2 induces its biological effects in particular via two receptor subtypes, i.e. angiotensin 2 receptor $1\left(\mathrm{AT}_{1} \mathrm{R}\right)$ and angiotensin 2 receptor $2\left(\mathrm{AT}_{2} \mathrm{R}\right)$. The stabilizing effects on hemodynamics during conditions of compromised circulation, like vasoconstriction, release of aldosterone and retention of salt and water are mainly mediated by interaction of angiotensin 2 with $\mathrm{AT}_{1} \mathrm{Rs}$. Likewise many of the pathologic, proinflammatory or proatherogenic effects of angiotensin 2 are thought to be mediated via $\mathrm{AT}_{1} \mathrm{Rs}$ (Weir 2007). Effects of the $\mathrm{AT}_{2} \mathrm{R}$ are less understood. Mainly $\mathrm{AT}_{2} \mathrm{R}$ activation mediates opposing effects of the $\mathrm{AT}_{1} \mathrm{R}$-like vasodilation and natriuresis (Carey 2017). The $\mathrm{AT}_{1} \mathrm{R}$ is widely distributed throughout the body. Therefore, inhibition of RAAS, precisely blocking the $\mathrm{AT}_{1} \mathrm{R}$ pathway is thought to be a promising concept to attenuate the disproportionate decrease in splanchnic mucosal perfusion during circulatory shock and might even preserve gastrointestinal organ function. A constantrate infusion of enalapril improves mesenteric blood flow during resuscitation from hemorrhagic shock in dogs (Wall et al. 2003). Systemic RAAS inhibition might even show deleterious effects on mucosal oxygenation. In a previous study we were able to demonstrate that intravenous application of captopril in otherwise healthy dogs strongly reduced gastric mucosal oxygenation (Vollmer et al. 2013a). In addition, systemic RAAS inhibition in the critically ill patient is limited due to considerably adverse side effects. Most prominent is a distinct reduction in blood pressure (Francis et al. 2004), which by itself might negatively affect gastrointestinal perfusion and oxygenation. To avoid systemic adverse side effects, topical drug application was established in a variety of different organs, like inhaled prostacyclin in pulmonary hypertension (Olschewski et al. 2000). Recently we were able to show that topical application of vasodilatory agents like the nitric oxide (NO)-donor nitroglycerin or iloprost improved $\mathrm{\mu HbO}_{2}$ during hemorrhagic shock in dogs (Truse et al. 2017). Thus, as splanchnic perfusion is mainly regulated by the RAAS during hemorrhage, topical application of losartan, a specific antagonist to the $\mathrm{AT}_{1} \mathrm{R}$, might be a promising concept to improve gastric perfusion at the microvascular level with markedly reduced systemic adverse side effects. The combination of different vasoactive agents (NO donor, RAAS inhibitor) to improve gastrointestinal microcirculation may reduce side effects of one drug and result in synergistic effects.

Taken together, the aim of this study was to evaluate the effect of topical RAAS inhibition with losartan during physiological conditions and hemorrhage on oral and gastric mucosal perfusion and oxygenation. As reduction of systemic blood pressure can directly impair splanchnic perfusion, the effect of topical $\mathrm{AT}_{1} \mathrm{R}$ inhibition on systemic hemodynamic variables was analyzed in parallel.

\section{Materials and methods}

\section{Animals}

The data were derived from repetitive experiments on six dogs (female foxhounds, weighing $28-36 \mathrm{~kg}$ ) treated in accordance with the NIH guidelines for animal care. Experiments were performed with approval of the Local Animal Care and Use Committee (North RhineWestphalia State Agency for Nature, Environment and Consumer Protection, Recklinghausen, Germany; ref. 84-02.04.2012.A152).

A slightly modified, well-established canine model of hemorrhagic shock was used as published previously (Schwartges et al. 2010). The anatomic conditions in dogs enable the nontraumatic placement of the measuring probe to the gastric mucosa without laparotomy. Additionally, larger blood sample volumes can be collected without hemodynamic side effects. Repetitive experiments are 
possible which reduce the number of experiments and hence the number of laboratory animals. There is no need to kill the animals at the end of the experiment. Prior to the experiments, access to food was withheld for $12 \mathrm{~h}$ with water ad libitum to ensure complete gastric depletion and to avoid changes in mucosal perfusion and oxygenation due to digestive activity and to allow the undisturbed coupling of the measuring probe to the mucosa. Each dog underwent each experimental protocol in a randomized order and served as its own control. The experiments were performed at least 3 weeks apart to prevent carryover effects. The experiments were performed under general anesthesia (induction of anesthesia with $4 \mathrm{mg} / \mathrm{kg}$ propofol, maintenance with sevoflurane, end-tidal concentration of 3.0\% (1.5 minimum alveolar concentration for dogs)). The dogs were mechanically ventilated $\left(\mathrm{FiO}_{2}=0.3\right.$, tidal volume $=12.5 \mathrm{ml} / \mathrm{kg}$, a normal tidal volume for dogs; Dyson 2012) after endotracheal intubation with the respiratory frequency adjusted to achieve normocapnia (end-expiratory carbon dioxide $\left(\right.$ etCO $\left.\mathrm{C}_{2}\right)=35 \mathrm{mmHg}$ ), verified by continuous capnography (Capnomac Ultima, Datex Instrumentarium, Helsinki, Finland). During baseline conditions, the dogs were placed on their right side and covered with isolating blankets to maintain the body temperature at $37.5^{\circ} \mathrm{C}$ (continuous arterial measurement). Throughout the experiments, no additional fluid replacement was carried out to avoid volume effects that could influence tissue perfusion and oxygenation. However, after withdrawal of each blood sample, normal saline was infused at three times the sampling volume to maintain blood volume.

\section{Measurements}

\section{Systemic hemodynamic and oxygenation variables}

The aorta was catheterized via the left carotid artery for continuous measurement of mean arterial pressure (MAP, Gould-Statham pressure transducers P23ID, Elk Grove, IL, USA) and intermittent arterial blood gas analysis (Rapidlab 860, Bayer AG, Germany). Cardiac output (CO) was determined via transpulmonary thermodilution (PiCCO 4.2 non US, PULSION Medical Systems, Munich, Germany) at the end of each intervention. Arterial oxygen content and systemic oxygen delivery $\left(\mathrm{DO}_{2}\right)$ were calculated subsequently. Heart rate (HR) was continuously measured by electrocardiography (Powerlab, ADInstruments, Castle Hill, Australia).

\section{Gastric and oral mucosal oxygenation and perfusion} Microcirculatory oxygenation $\left(\mu \mathrm{HbO}_{2}\right)$ and perfusion ( $\mu$ flow) of the gastric and oral mucosa were continuously assessed by tissue reflectance spectrophotometry and laser Doppler flowmetry (O2C, LEA Medizintechnik, Gießen, Germany), as described previously (Krug 2006). Briefly, white light (450-1000 nm) and laser light $(820 \mathrm{~nm}$, $30 \mathrm{~mW}$ ) were transmitted to the tissue of interest via a micro-light guide and the reflected light was analyzed. The wavelength-dependent absorption and overall absorption of the applied white light can be used to calculate the percentage of oxygenated hemoglobin $\left(\mu_{\mathrm{HbO}_{2}}\right)$. Due to the Doppler effect, magnitude and frequency distribution of changes in wavelength are proportional to the number of blood cells multiplied by the measured mean velocity ( $\mu v e l o$ ) of these cells. This product is proportional to flow (uflow) and expressed in arbitrary perfusion units (aU). Hence, this method allows assessment and comparison of oxygenation and perfusion of the examined region at the same time. Since light is totally absorbed in vessels with a diameter $>100 \mu \mathrm{m}$ only microvascular oxygenation of nutritive vessels of the mucosa is measured. The biggest fraction of the blood volume is stored in venous vessels; therefore, mainly postcapillary oxygenation is measured which represents the critical partial pressure of oxygen $\left(\mathrm{pO}_{2}\right)$ for ischemia. One flexible light guide probe was placed in the mouth facing the buccal side of the oral mucosa and a second probe was introduced into the stomach via an orogastric tube. Online evaluation of the signal quality throughout the experiments allowed verification of the correct position of the probe tip. The $\mu \mathrm{HbO}_{2}$ and $\mu$ flow values reported are the means of the last $5 \mathrm{~min}$ (150 spectra, $2 \mathrm{~s}$ each) of the respective intervention under steady-state conditions. The nontraumatic access to the gastric mucosa allowed the determination of mucosal microcirculation in the absence of surgical stress. This is particularly desirable with respect to the marked alterations that surgical stress exerts on splanchnic circulation. In this situation reflectance spectrophotometry reliably detects even clinically asymptomatic reductions in $\mu \mathrm{HbO}_{2}$ (Fournell et al. 2003) and highly correlates with the morphologic severity and extent of gastric mucosal tissue injury (Sato et al. 1986).

\section{Oral mucosal microcirculation - videomicroscopy}

Microcirculatory perfusion of the oral, buccal mucosa was consecutively measured by incident dark field (IDF) imaging (CytoCam, Braedius Medical, Huizen, Netherlands) as described elsewhere (Aykut et al. 2015). Illumination was provided by light-emitting diodes at a wavelength of $530 \mathrm{~nm}$, the isobestic point for deoxy- and oxyhemoglobin and directed toward the oral mucosa. The reflected and scattered light was filtered and pictures 
red blood cells in capillaries. All videos were obtained by the same operator and stored anonymized for blinded analysis. The microcirculation was measured according to the round table guidelines as published by De Backer et al. (2007). To assess perfusion, a semiquantitative scoring method, the microcirculatory flow index (MFI) was used to characterize microcirculatory flow as 'no flow', 'intermittent flow', 'sluggish flow' and 'continuous

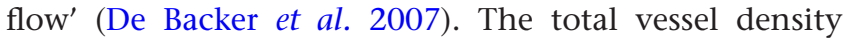
(TVD), including perfused and non-perfused microvessels, and perfused vessel density (PVD), including perfused microvessels only, was analyzed using dedicated software (MicroCirculation Analysis software, Braedius Medical, Huizen, Netherlands) (Carsetti et al. 2015). The ratio PVD/ TVD was used to express the proportion of perfused vessels (PPV). Only vessels with a diameter smaller than $20 \mu \mathrm{m}$ were included in the analysis, so the PVD represents the functional capillary density, considered to be the main determinant of microcirculatory blood supply (Bezemer et al. 2012).

\section{Intestinal barrier function}

The disaccharide lactulose $(16.7 \mathrm{mg} / \mathrm{kg}$, Bifiteral, Abbott Germany, Ludwigshafen, Germany) and the monosaccharides rhamnose $(6.7 \mathrm{mg} / \mathrm{kg}, \mathrm{L}(+)$-rhamnose monohydrate, Carl Roth, Karlsruhe, Germany), mannitol $(6.7 \mathrm{mg} / \mathrm{kg}$, Mannit-Solution 15\%, Serag-Wiessner, Naila, Germany) and xylose (66.7 mg/kg, D(+)-xylose, Carl Roth, Karlsruhe, Germany) were infused into the stomach via an orogastric tube prior to the induction of hemorrhagic shock. Lactulose is a parameter of paracellular permeability, thereby indicating passive absorption of larger molecules. Rhamnose, mannitol and D-xylose are passively absorbed mainly via transcellular permeation with negligible affinity for the monosaccharide transport system, indicating the degree of absorption of small molecules. These saccharides are not further metabolized. Plasma levels can therefore be used to assess altered intestinal barrier function under pathologic conditions (Marsilio et al. 1998).

Blood samples were collected under baseline conditions and during hemorrhagic shock. The collected samples were prepared as previously described (Brilhaus et al. 2016). Briefly, blood samples were stored in small tubes (Vacutainer K2E EDTA $18.0 \mathrm{mg}$, Plymouth, UK) and plasma was separated via centrifugation at $0^{\circ} \mathrm{C}$ and $3000 \mathrm{~g}$ for $15 \mathrm{~min}$ (Rotina 420R, Hettich Zentrifugen, Mülheim a.d. R., Germany). Cold extraction solvent mixture containing $10 \mu \mathrm{M}$ ribitol (Adonitol, Carl Roth, Karlsruhe, Germany) as internal standard, acetone (Aceton, Carl
Roth) and isopropanol (2-Propanol, Carl Roth) at a ratio of 2:1 were freshly prepared before use and $0.4 \mathrm{~mL}$ were added to each sample containing $30 \mu \mathrm{L}$ plasma. Samples were shaken for $5 \mathrm{~min}$ at $4^{\circ} \mathrm{C}$ prior to centrifugation at $20,800 \boldsymbol{g}$ for $2 \mathrm{~min}$. The liquid supernatant was collected, degassed with a gentle stream of nitrogen (Stickstoff verdichtet, Linde AG, Pullach, Germany) and stored at $-80^{\circ} \mathrm{C}$ for later analysis. After resuspension, aliquots of the extracts were dried using a speed vacuum concentrator, measured by gas chromatography-mass spectrometry (GC-MS) and analyzed using an appropriate software as described elsewhere (Brilhaus et al. 2016). Results are presented as relative amount $/ \mu l$ plasma.

\section{Induction of hemorrhagic shock}

Hemorrhagic shock was induced by removing $20 \%$ of the estimated total blood volume via a large bore intravenous cannula in a peripheral vein and the arterial catheter (i.e. $16 \mathrm{ml} / \mathrm{kg}$ of whole blood over five min). According to Advanced Trauma Life Support this model represents a class II shock (Kortbeek et al. 2008). This reversible and non-lethal shock model allows the investigation of either protective or harmful effects of various interventions. Heparinized shed blood was stored and later retransfused using an infusion set with a $200 \mu \mathrm{m}$ filter.

\section{Experimental protocol}

After instrumentation, $30 \mathrm{~min}$ were allowed to establish steady-state conditions and baseline values were recorded before the animals were randomized to the respective protocol (Fig. 1). Steady-state conditions were defined as stability of hemodynamic variables as well as ventilation parameters. Subsequently, saccharides were administered as described earlier, followed by further $30 \mathrm{~min}$ to establish stable measurement in the gastric region.

The investigators were blinded concerning the applied drug during the experiment and later analysis.

\section{Losartan (L)}

To study the effects of losartan, after 90-min stable baseline conditions the animals received a gastric and oral bolus of $30 \mathrm{mg}$ losartan solved in $1 \mathrm{ml} \mathrm{NaCl} 0.9 \%$ and all variables were recorded for the next $90 \mathrm{~min}$ (Fig. 1). Losartan was applied next to the site of the microcirculation measurement. The gastric bolus reached the stomach via a gastric tube fixed to the $\mathrm{O} 2 \mathrm{C}$ probe, whereas the bolus to the oral mucosa was applied around the measuring point via a perforated silicon tube. 


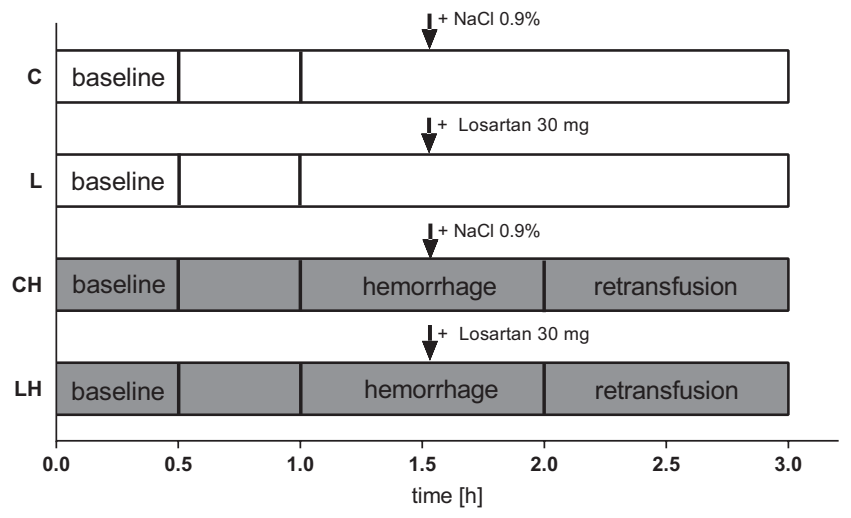

Figure 1

Experimental protocol: Application of normal saline (C) or losartan (L) during physiological conditions or during hemorrhagic shock with additional application of normal saline (CH) or iloprost ( $\mathrm{LH}), \downarrow$ bolus application to the oral and gastric mucosa.

\section{Control experiment (C)}

As time control experiment, only the vehicle $(\mathrm{NaCl}$ $0.9 \%$ ) was applied via the same route of administration as described for losartan and all variables were recorded for $90 \mathrm{~min}$.

\section{Losartan + hemorrhagic shock (LH)}

To study the effect of $\mathrm{AT}_{1} \mathrm{R}$ blockade on hemorrhage and retransfusion, losartan was injected $30 \mathrm{~min}$ after induction of hemorrhagic shock. Hemorrhage was maintained for further $30 \mathrm{~min}$ followed by retransfusion of the shed blood with an additional observation period of $60 \mathrm{~min}$.

\section{Control experiment, hemorrhagic shock (CH)}

To study the effects of hemorrhage alone, only the vehicle was injected during hemorrhage followed by retransfusion as described above.

Blood samples were taken every $30 \mathrm{~min}$ for blood gas analysis.

\section{Statistical analysis}

Data for analysis were obtained during the last $5 \mathrm{~min}$ of baseline and intervention periods under steady-state conditions. All data are presented as absolute values of mean \pm s.E.M. for six dogs. Differences within the groups and between the groups were tested using a two-way analysis of variance for repeated measurements (ANOVA) and a Bonferroni test as post hoc analysis (GraphPad Prism version 6.05 for Windows, GraphPad Software). An a priori power analysis ( $\mathrm{G}^{*}$ Power Version 3.1.9.2) revealed a power of 0.85 for detection of differences between the different groups with $n=6$ in 4 groups, repeated measurements, $\alpha<0.05$ and $\eta^{2}$ of 0.5 (calculated from previous experiments).

\section{Results}

During physiological conditions, losartan transiently increased gastric pflow from $99 \pm 6 \mathrm{aU}$ to $147 \pm 17 \mathrm{aU}$ $(P<0.05) \quad 10 \mathrm{~min}$ after application. This effect was
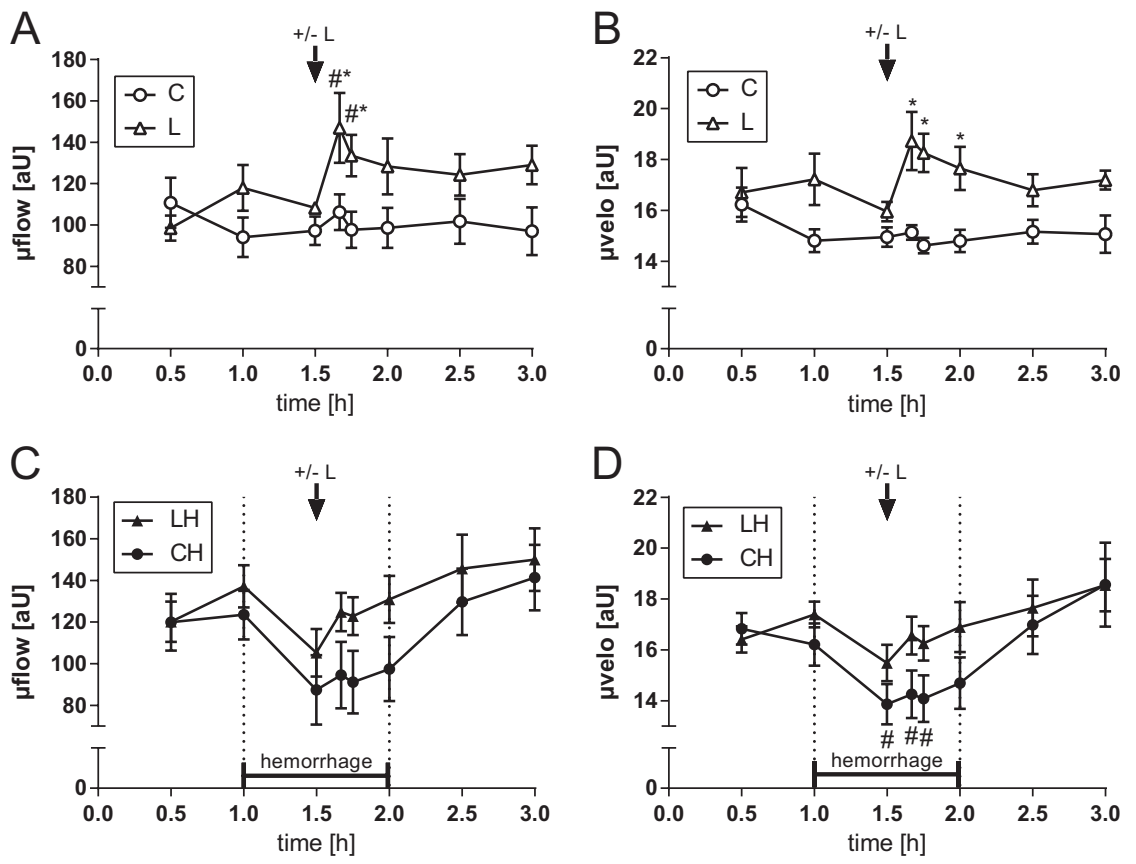

Figure 2

Gastric $\mu$ flow and $\mu$ velo. Gastric microcirculatory flow ( $\mu$ flow) and gastric microcirculatory velocity ( $\mu$ velo) in anesthetized dogs during normovolemia ( $A$ and $B$ ) and during hemorrhagic shock ( $C$ and $D)$ with topical application $(\downarrow \pm \mathrm{L})$ of vehicle $(\mathrm{C}, \mathrm{CH})$ or losartan (L, LH). Data are presented as mean \pm s.E.M. for $n=6$ dogs; $\# P<0.05$ vs baseline, $\star P<0.05$ vs respective control group (vs $C$ for $L$, vs $\mathrm{CH}$ for $\mathrm{LH}$ ), two-way ANOVA for repeated measurements followed by Bonferroni post hoc test. 
detectable until 15 min after application. Thirty minutes after application of losartan no differences were found between intervention and control group values (Fig. 2A). In parallel to gastric microcirculatory perfusion, losartan enhanced gastric pvelo from $17 \pm 1 \mathrm{aU}$ to $19 \pm 1 \mathrm{aU}$ $(P<0.05$, Fig. 2B). This effect lasted for $30 \mathrm{~min}$. Control group values remained stable during the experiment. In contrast to gastric perfusion, losartan had no effect on gastric oxygenation (Table 1). Local $\mathrm{AT}_{1} \mathrm{R}$ blockade with losartan had no significant effect on oral microvascular perfusion or oxygenation. A transient decrease in oral uflow compared to baseline values was observed $15 \mathrm{~min}$ after application of losartan, however, without differences to the control group (Table 1). The oral vascular density parameters TVD and PVD and the perfusion parameters MFI and PPV remained unchanged during physiological conditions and after losartan treatment (Table 1). Topical application of losartan had no effect on systemic hemodynamic variables (Fig. $3 \mathrm{~A}$ and $\mathrm{B}$ ). $\mathrm{MAP}, \mathrm{DO}_{2}, \mathrm{CO}$ and SVR remained stable throughout the experiment (Table 2).

A detailed presentation of micro- and macrovascular parameters and further metabolic and respiratory variables is given in Tables 1 and 2 .

Gastric $\mu$ velo was significantly decreased during hemorrhage from $17 \pm 1 \mathrm{aU}$ to $14 \pm 1 \mathrm{aU}(\mathrm{CH}, P<0.05)$. Topical treatment with losartan did not improve $\mu$ velo compared to baseline values and to the control group (Fig. 2D 4). Induction of a mild hemorrhagic shock had no significant effect on gastric $\mu$ flow (decrease from $120 \pm 14 \mathrm{aU}$ to $87 \pm 17 \mathrm{aU}, P=0.12$ ) (Fig. 2C 4). After application of losartan, gastric microcirculatory perfusion tended to be higher compare to the control group, but this increase was not significant $(P=0.09)$. In hemorrhagic shock, gastric mucosal oxygenation was reduced in both groups from $83 \pm 2 \%$ to $52 \pm 2 \%(\mathrm{CH}, P<0.05)$ and from $80 \pm 2 \%$ to $48 \pm 6 \%$ (LH, $P<0.05$ ). After administration of losartan, local gastric $\mu \mathrm{HbO}_{2}$ remained depressed during hemorrhage $(56 \pm 7 \%)$ similar to the control group $(57 \pm 6 \%)$ (Table 1$)$.

Hemorrhage let to a pronounced reduction in oral perfusion. Oral uflow decreased from $179 \pm 26 \mathrm{aU}$ to $70 \pm 21$ aU (LH, $P<0.05)$ without differences to the control group (decrease from $167 \pm 28 \mathrm{aU}$ to $89 \pm 29 \mathrm{aU}, P<0.05$ ). Application of losartan did not increase oral $\mu$ flow $(80 \pm 21 \mathrm{aU}$ vs $99 \pm 33 \mathrm{aU}$ in the control group, $P>0.05$ ). Likewise, oral $\mu$ velo decreased from $29 \pm 4$ to $19 \pm 3 \mathrm{aU}$ (LH, $P<0.05)$ and from $29 \pm 4$ to $20 \pm 4$ aU $(\mathrm{CH}, P<0.05)$ without differences between the groups and was not restored by losartan $(19 \pm 3$ aU vs $21 \pm 4$ in the control group, $P>0.05)$
(Table 1). Similar to gastric mucosal oxygenation, losartan had no effect on oral $\mu \mathrm{HbO}_{2}$ during hemorrhagic shock. Oral buccal capillary density and oral perfusion measured with IDF were strongly reduced during hemorrhage. Topical application of losartan did not improve capillary density (TVD), overall capillary perfusion (PVD, PPV) or flow quality (MFI) (Table 1).

During hemorrhage $\mathrm{DO}_{2}$ decreased to a similar degree in all groups: from $13 \pm 1$ to $7 \pm 1 \mathrm{ml} / \mathrm{kg} / \mathrm{min}(\mathrm{CH}, P<0.05)$ and from $12 \pm 1$ to $6 \pm 1 \mathrm{ml} / \mathrm{kg} / \mathrm{min}$ (LH, $P<0.05$ ). The decrease in $\mathrm{DO}_{2}$ was accompanied by a similar decrease in $\mathrm{CO}$ (Fig. 3C). After retransfusion $\mathrm{DO}_{2}$ was restored similarly to $13 \pm 1 \mathrm{ml} / \mathrm{kg} / \mathrm{min}(\mathrm{CH})$ and $13 \pm 2 \mathrm{ml} / \mathrm{kg} / \mathrm{min}$ (LH) (Table 2). After application of losartan, no differences in hemodynamic variables were found compared to the control group. Particularly local application of losartan had no acute effects on MAP (Fig. 3D). Directly after administration of losartan, MAP was not different compared to the control group $(52 \pm 2 \mathrm{mmHg}$ vs. $53 \pm 2 \mathrm{mmHg}, P>0.05)$. Likewise, no differences were observed $90 \mathrm{~min}$ after losartan application (LH: $64 \pm 1 \mathrm{mmHg}$ vs $\mathrm{CH}: 66 \pm 2 \mathrm{mmHg}, P>0.05$ ).

\section{Intestinal barrier function}

Plasma levels of rhamnose, lactulose and mannitol were below the detection limit of the GC-MS. Xylose plasma levels show a high variability among all groups without a detectable increase during hemorrhage (Fig. 4).

A detailed presentation of micro- and macrovascular parameters and further metabolic and respiratory variables is given in Tables 1 and 2 .

\section{Discussion}

This investigation was performed to test the hypothesis that local blockade of $\mathrm{AT}_{1} \mathrm{R}$ via topical application of losartan influences oral and gastric microcirculation and intestinal barrier function during hemorrhagic shock without systemic side effects. We could show that losartan significantly increased gastric $\mu$ flow during physiological conditions. This went along with an increased gastric $\mu$ velo compared to the control group. During mild hemorrhage topical treatment with losartan prevented the shock-induced decrease in gastric $\mu v e l o$ but did not significantly increase gastric $\mu$ flow. Effects on microcirculatory perfusion were not accompanied by changes in systemic hemodynamic variables, which remained stable throughout the experiment. 


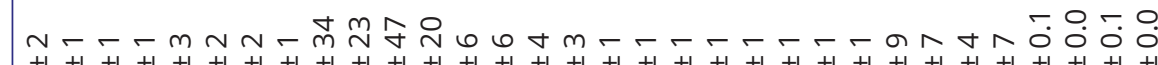

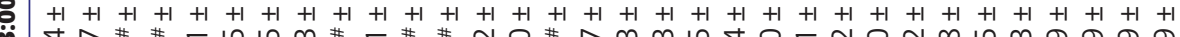

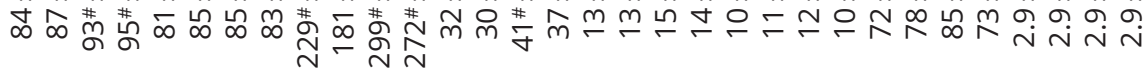

$$
\text { กิ }
$$

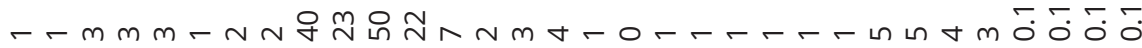

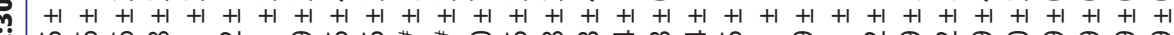
央$$
\text { N }
$$

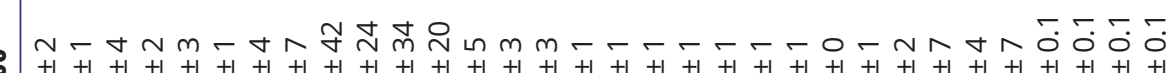

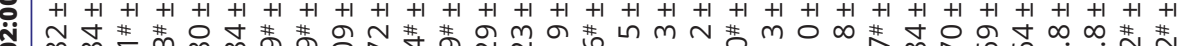

2

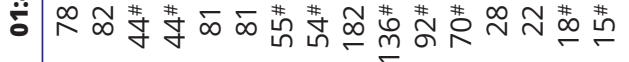

2

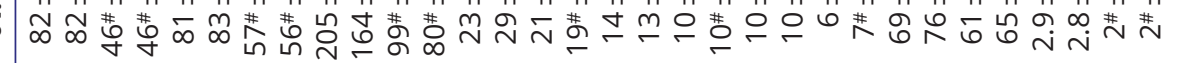

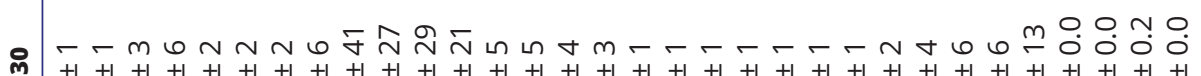

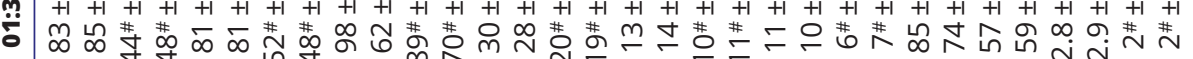

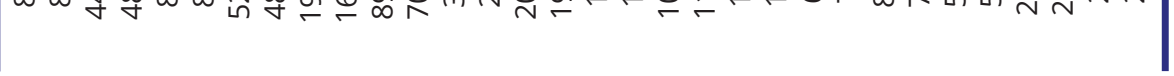

\section{|} 응 웅

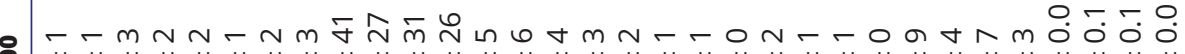
$1+1+1+1+1+1+1+1+1+1+1+1+1+1+1+1+1+1+1+1+1+1+1+1+1+1+1+1+1+1+1+1$ ゆ

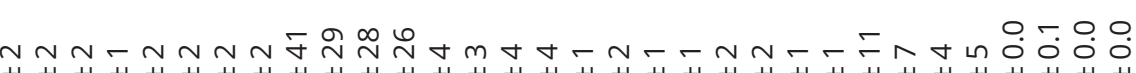

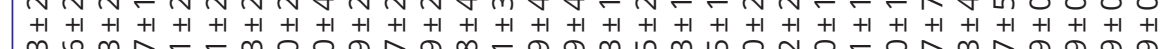

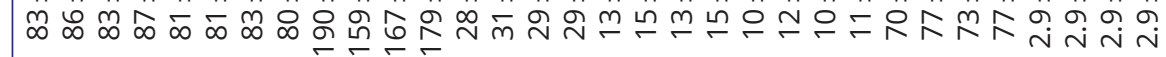

ปั $\mid$ 

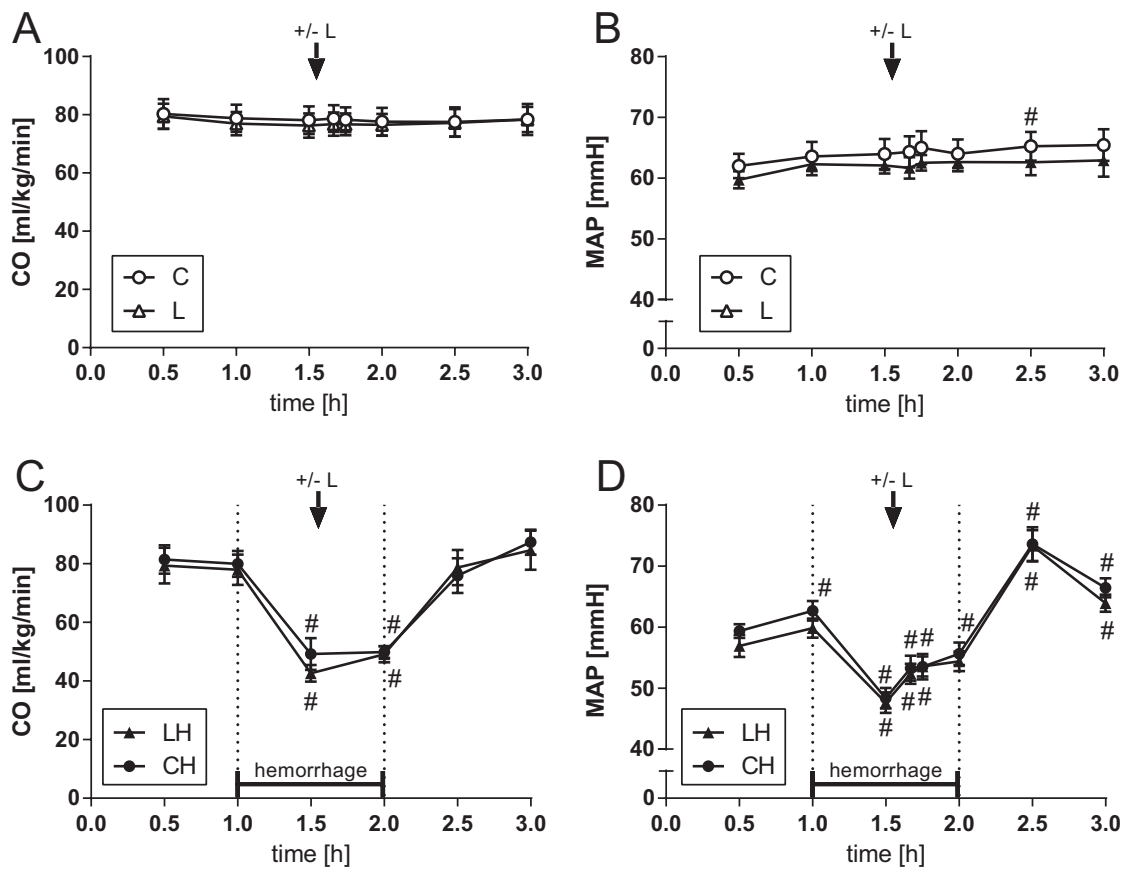

Figure 3
Cardiac output and mean arterial pressure.
Cardiac output (CO) and mean arterial pressure
(MAP) in anesthetized dogs during otherwise
physiologic conditions (A and B) and during
hemorrhagic shock ( $C$ and $D$ ) with topical
administration $(\downarrow \pm L)$ of vehicle $(C, C H)$ or losartan
(L, LH). Data are presented as mean \pm S.E.M. for
$n=6$ dogs; $\# P<0.05$ vs baseline, two-way ANOVA
for repeated measurements followed by
Bonferroni post hoc test.

In our investigation, $30 \mathrm{mg}$ losartan each were administered locally to the oral and gastric mucosa; this dose is within the range of daily clinical routine (Konstam et al. 2009). Gastric microvascular perfusion increased directly after topical application of losartan during physiological conditions. As peak plasma concentrations of losartan appear at 60-90 min after oral application (Lo et al. 1995), this early-onset short-lasting modulation of gastric perfusion most likely indicates blockade of locoregional $\mathrm{AT}_{1} \mathrm{R}$. $\mathrm{AT}_{1} \mathrm{R}$ are known to be highly expressed especially in the splanchnic vasculature (Reilly \& Bulkley 1993). Thus, vasotone regulation was probably modified via $\mathrm{AT}_{1} \mathrm{R}$ at the level of the microcirculation rather than via systemic effects on major upstream vessels. Growing evidence supports the existence of local RAAS in various tissues and new bioactive angiotensin metabolites, like Ang-(1-7) (Ferrario \& Chappell 2004). Inside the stomach wall, angiotensin 1 is metabolized predominantly to Ang-(1-7) and to a minor part to angiotensin 2 (Olszanecki et al. 2009). Ang-(1-7) exerts vasoactive and tissue protective properties via Mas-receptor activation (Pawlik et al. 2016). In the context of local gastric $\mathrm{AT}_{1} \mathrm{R}$ inhibition, this alternative pathway may have a relevant effect on local microcirculation. Beside the reduced activity of angiotensin 2 , treatment with $\mathrm{AT}_{1} \mathrm{R}$ inhibitors improved endothelial function (Hornig et al. 2001) and NO-mediated vasodilation via enhanced expression of endothelial NO synthase (Thai et al. 2003). The effect of losartan on gastric perfusion is diminished during hemorrhagic shock.
Especially during conditions of compromised perfusion and intensified sympathetic activity like hemorrhage, one must assume angiotensin 2 blockade to gain more influence on vascular tone. Our results do therefore not agree with other studies, which demonstrate increased jejunal mucosal blood flow during hypovolemia in pigs after systemic angiotensin 2 inhibition (Aneman et al. 2000, Laesser et al. 2000). However, these studies are focusing on intestinal perfusion with the predominant role of the superior mesenteric artery rather than gastric perfusion via the coeliac trunk. Furthermore, we used a therapeutic treatment regime with losartan applied topically during hemorrhagic shock, whereas Laesser et al. and Aneman et al. used a pretreatment protocol of systemic candesartan administration prior to a pronounced hypovolemia (Aneman et al. 2000, Laesser et al. 2000). As resistance arterioles are the predominant determinant of microvascular resistance (Ceppa et al. 2003), a pronounced vasoconstriction upstream the mucosal capillary bed might disguise a potential losartanmediated local vasodilation in the capillary bed. As losartan acts as a competitive antagonist, the dose chosen in this experiment might be insufficient in the context of increased angiotensin 2 levels during hemorrhagic shock. Furthermore, during conditions of hemorrhage, regulation of splanchnic blood flow is complex with a special involvement of vasopressin (Francis et al. 2004) which is known to diminish mesenteric blood flow in the upper gastrointestinal tract (Hiltebrand et al. 2007). 


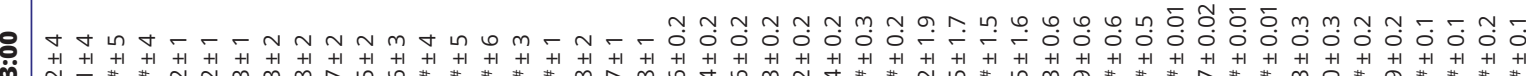

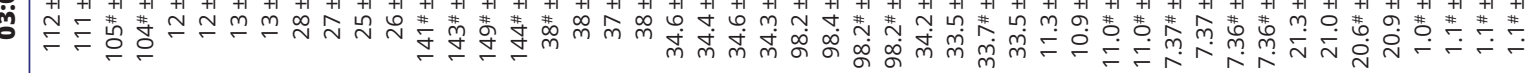

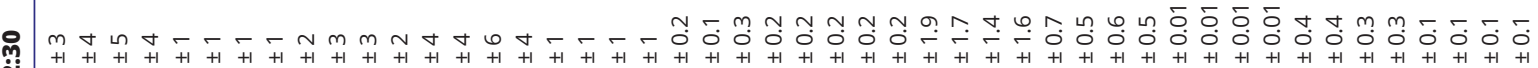

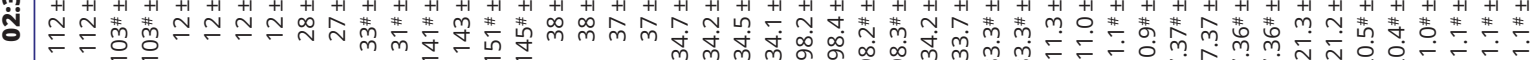

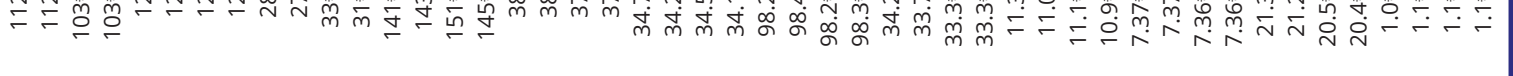

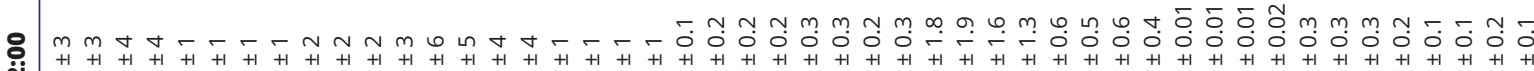

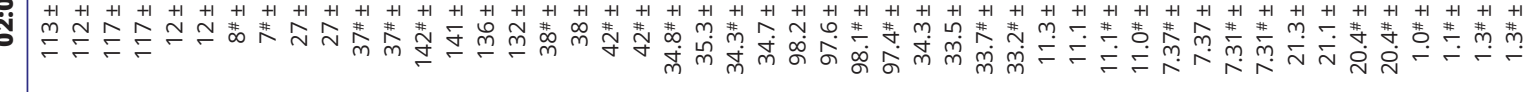

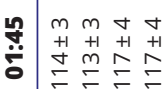

$\begin{array}{cccc}m & m & m & m \\ 0 & 0 & 0 & 0 \\ ++1 & +1 & +1 & +1\end{array}$

岗

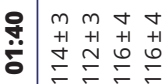

กับ

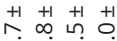

官官官家

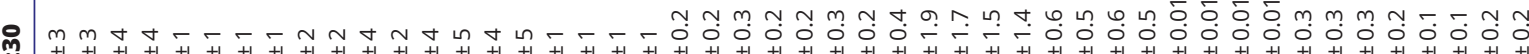

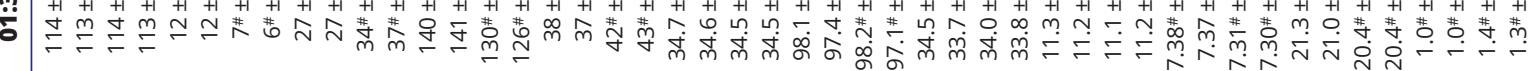

$m m m m \ldots \ldots+\ldots n N$ n

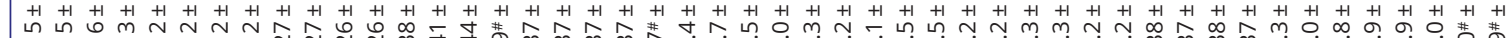

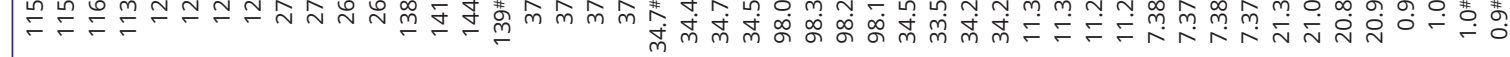

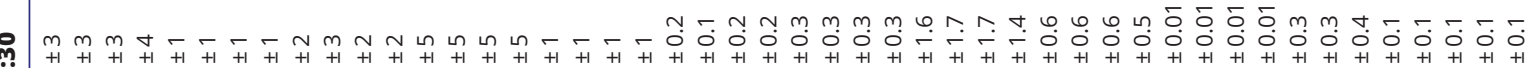

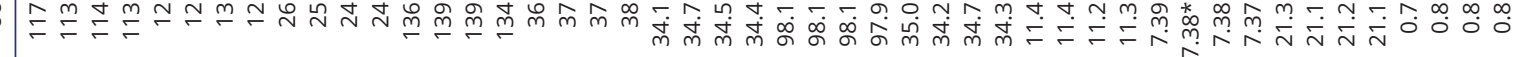

\section{$\frac{\sqrt{\frac{\pi}{\varepsilon}}}{\frac{\varepsilon}{2}}$}




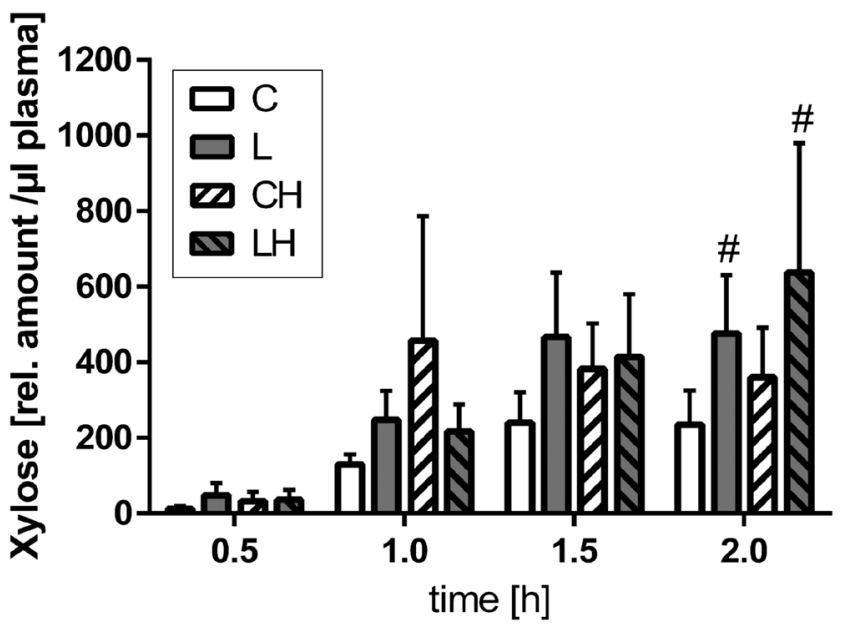

Figure 4

Xylose plasma levels. Xylose plasma levels during baseline conditions, after application of the saccharide solution and during the next $60 \mathrm{~min}$. Data are presented as mean \pm S.E.M. for $n=6$ dogs; $\# P<0.05$ vs. baseline, two-way ANOVA for repeated measurements followed by Bonferroni post hoc test.

Therefore, altered microcirculatory perfusion by vasopressin or other vasoactive mediators might outweigh potential beneficial effects of local RAAS inhibition.

As topical treatment with losartan had no significant effects on systemic hemodynamic variables, especially $\mathrm{DO}_{2}$, one would expect that an increased microvascular perfusion results in increased local oxygenation. However, our data reveal that in the presence of losartan, $\mu \mathrm{HbO}_{2}$ did neither increase during normovolemia nor in hemorrhagic shock. Since the gastrointestinal microcirculation is composed of series- and parallel-coupled circuits (Ceppa et al. 2003), angiotensin 2 inhibition might open shunts, thereby bypassing the oxygenated blood and impede a net increase in postcapillary microcirculatory oxygenation. Despite modulation of oxygen supply, altered oxygen utilization might account for our findings. Angiotensin 2 is known to impair mitochondrial respiratory activity (Inoue et al. 2012). Treatment with $\mathrm{AT}_{1} \mathrm{R}$ antagonists could improve mitochondrial function in rat kidneys (de Cavanagh et al. 2003) and murine skeletal muscle (Takada et al. 2013). As these studies investigated the long-term treatment in a chronic murine and rat model, these results cannot be easily transferred to our model of healthy dogs. Therefore, it remains speculative whether a losartaninduced rise in mitochondrial respiratory activity with increased oxygen consumption superposed the raised oxygen supply.

$\mathrm{AT}_{1} \mathrm{R}$ antagonists are well known to induce gastric mucosal protective effects. Continuous subcutaneous application of candesartan for 14 days increased blood flow to the stomach and reduced the number of gastric ulcers in rats submitted to cold-restraint stress (Bregonzio et al. 2003). Intestinal mucosal barrier function was evaluated by measuring the permeability of saccharide molecules (Marsilio et al. 1998). In the present study plasma levels for mannitol, rhamnose and lactulose were below the limit of detection, probably indicating only minor damage to the mucosal barrier. Xylose plasma levels showed no consistent increase during hemorrhage. This is unexpected as D-xylose plasma levels are known to indicate damage to the intestinal mucosal barrier (Li et al. 2008). A rather large and variable passive oral reflux of the saccharide solution through the inserted orogastric tube might substantially reduce the effective applied saccharide dose. Intestinal content with high osmolarity is known to increase intestinal permeability by itself even in the absence of pathologic factor (Pappenheimer \& Reiss 1987). Therefore, these technical limitations do not allow a safe interpretation of the measured values.

In the present study, a single application of losartan to the gastric mucosa caused a prompt but short-lasting increase in gastric mucosal blood flow. Distribution in the entire stomach with a consecutive decrease in local mucosal drug concentration most likely causes the short duration of the observed effect. A sustained topical substitution of losartan might cause different effects. As losartan has a rather low per os bioavailability and up to $29 \%$ are directly excreted with the stool (Christ et al. 1994), topical treatment might even be suitable for further aboral parts of the intestine. However, the use of a higher dose is limited most likely due to adverse systemic side effects.

Conflicting evidence exists concerning the impact of elevated systemic angiotensin 2 levels during circulatory shock. Angiotensin 2 was successfully used as a rescue approach in catecholamine-refractory shock (Thomas \& Nielsen 1991). On the other hand, RAAS blockade showed organ protective effects (Laesser et al. 2004). But treatment with orally administered enalapril worsened the severity of hypotension in resuscitated porcine septic shock (Corrêa et al. 2014). Considering these conflicting results, systemic RAAS inhibition might promote negative effects on microcirculation and organ function via reduction of the perfusion pressure, especially during pathologic conditions like septic or hemorrhagic shock.

Topical application of losartan increased $\mu$ flow and $\mu$ veloofgastricmucosalmicrocirculationduring physiologic conditions. In contrast, although mild hemorrhage reduced oral regional perfusion (overall microcirculatory perfusion ( $\mu$ flow) and velocity ( $\mu$ velo)) and even revealed a 
pronounced reduction of the oral microvascular capillary density (TVD, PVD), no effect of a treatment with losartan could be observed. Oral microcirculation is used as an indicator of microcirculation of other regions of the gastrointestinal tract (Verdant et al. 2009). However, we have previously shown different reaction patterns of oral and gastric oxygenation and perfusion during hemorrhage (Vollmer et al. 2013b, Truse et al. 2017). Thus, the present study provides further evidence that oral microcirculation is not an indicator of gastrointestinal microcirculation and organ function per se.

Our study has several limitations. The sample size of $n=6$ animals per group seems to be rather small compared to usual sample sizes in non-repetitive experiments, for example, using rats. However, the cross-over design allows sufficient power for small sample sizes, as each animal serves as its own control. However, the study was not powered to detect subtle, clinically irrelevant differences. The impact of hemorrhage is moderate, as this is a nonlethal animal model. Thus, application of $\mathrm{AT}_{1} \mathrm{R}$ antagonists might have more impact on splanchnic perfusion in more severe levels of hemorrhagic shock. Nevertheless, the small sample size was sufficient to detect significant differences. In this animal model even mild improvement of microvascular flow or oxygenation seems relevant for barrier function (Truse et al. 2017, Vollmer et al. 2017). Hemorrhagic shock did not result in an increase in HR. This could, at least partially be explained by sevofluraneinduced depression of the baroreflex (Umehara et al. 2006). This phenomenon has been observed in this animal model under hemorrhagic shock before and might be related to the rather mild shock (Vollmer et al. 2013b, Truse et al. 2017). No relevant changes in hemoglobin and hematocrit were observed during acute hemorrhage. The decrease of Hct in hypovolemia is mainly caused by a delayed shifting of interstitial fluid into the vascular compartment, thereby increasing plasma volume (Cordts et al. 1992). Therefore, Hct measurements do not represent the blood volume during acute hemorrhage by all means. With respect to the drug, different dosing regimens of losartan, especially long-term or continuous application may also have different effects; although the dose used in this study is based on sound pharmacological data, no data are available for dogs, so far. The mechanism of action of losartan and direct effects on gastric mucosal cell integrity was not further studied, as this chronic, non-lethal animal model did not allow sample taking for histologic analysis. To elucidate selective effects on splanchnic microcirculation and tissue integrity, further studies in small rodents are planned, to allow the measurement of coeliac trunk and mesenteric artery blood flow via microflow probes and enable histological analysis of the gastric and intestinal mucosa.

Taking together, topical treatment of the gastric mucosa with losartan improves mucosal microcirculatory perfusion in anesthetized dogs, without significant effects on systemic hemodynamic variables. Thus, this demonstrates the regional role of $\mathrm{AT}_{1} \mathrm{R}$ and that modification of vascular tone via $\mathrm{AT}_{1} \mathrm{R}$ is possible at the level of the microcirculation. These results may allow to generate hypothesis on how local modulation of microcirculatory perfusion with $\mathrm{AT}_{1} \mathrm{R}$ antagonists could improve future treatment of human patients.

\section{Declaration of interest}

The authors declare that there is no conflict of interest that could be perceived as prejudicing the impartiality of the research reported.

\section{Funding}

This work was supported by departmental funds and by a grant of the Strategic Research Fund, Heinrich-Heine-University (No. 1229) to Christian Vollmer.

\section{Acknowledgments}

The authors thank Dr Pablo Verde (Head of Biostatistics, Coordinating Centre for Clinical Trials, University Hospital Duesseldorf) for guidance and review of statistical analysis. We thank Birgitt Berke for consultation and assistance during planning, conducting and analysis of the study. They are also grateful for the technical assistance of Katrin Weber, Elisabeth Klemp and Maria Graf in GC-MS metabolite analysis. This work was performed in partial fulfillment of the requirements of an MD thesis of Fabian Voß.

\section{References}

Ackland G, Grocott MP \& Mythen MG 2000 Understanding gastrointestinal perfusion in critical care: so near, and yet so far. Critical Care 4 269-281. (https://doi.org/10.1186/cc709)

Aneman A, Svensson M, Broomé M, Biber B, Petterson A \& Fändriks L 2000 Specific angiotensin II receptor blockage improves intestinal perfusion during graded hypovolemia in pigs. Critical Care Medicine 28 818-823. (https://doi.org/10.1097/00003246-200003000-00034)

Aykut G, Veenstra G, Scorcella C, Ince C \& Boerma C 2015 Cytocam-IDF (incident dark field illumination) imaging for bedside monitoring of the microcirculation. Intensive Care Medicine Experimental 340. (https://doi.org/10.1186/s40635-015-0040-7)

Bailey RW, Bulkley GB, Hamilton SR, Morris JB \& Haglund UH 1987 Protection of the small intestine from nonocclusive mesenteric ischemic injury due to cardiogenic shock. American Journal of Surgery 153 108-116. (https://doi.org/10.1016/0002-9610(87)90210-8)

Bezemer R, Bartels SA, Bakker J \& Ince C 2012 Clinical review: clinical imaging of the sublingual microcirculation in the critically ill - where do we stand? Critical Care 16 224. (https://doi.org/10.1186/cc11236) 
Bregonzio C, Armando I, Ando H, Jezova M, Baiardi G \& Saavedra JM 2003 Anti-inflammatory effects of angiotensin II AT1 receptor antagonism prevent stress-induced gastric injury. American Journal of Physiology: Gastrointestinal and Liver Physiology 285 G414-G423. (https://doi.org/10.1152/ajpgi.00058.2003)

Brilhaus D, Bräutigam A, Mettler-Altmann T, Winter K \& Weber APM 2016 Reversible burst of transcriptional changes during induction of crassulacean acid metabolism in Talinum triangulare. Plant Physiology 170 102-122. (https://doi.org/10.1104/pp.15.01076)

Carey RM 2017 AT2 receptors: potential therapeutic targets for hypertension. American Journal of Hypertension 30 339-347. (https:// doi.org/10.1093/ajh/hpw121)

Carsetti A, Pierantozzi S, Aya H, Bazurro S, Donati A, Rhodes A \& Cecconi M 2015 Accuracy of an automatic analysis software to detect microvascular density parameters. Intensive Care Medicine Experimental 3 A415. (https://doi.org/10.1186/2197-425X-3-S1-A415)

Ceppa EP, Fuh KC \& Bulkley GB 2003 Mesenteric hemodynamic response to circulatory shock. Current Opinion in Critical Care 9 127-132. (https://doi.org/10.1097/00075198-200304000-00008)

Christ DD, Wong PC, Wong YN, Hart SD, Quon CY \& Lam GN 1994 The pharmacokinetics and pharmacodynamics of the angiotensin II receptor antagonist losartan potassium (DuP 753/MK 954) in the dog. Journal of Pharmacology and Experimental Therapeutics 268 1199-1205.

Cordts PR, LaMorte WW, Fisher JB, DelGuercio C, Niehoff J, Pivacek LE, Dennis RC, Siebens H, Georgio A \& Valeri CR 1992 Poor predictive value of hematocrit and hemodynamic parameters for erythrocyte deficits after extensive elective vascular operations. Surgery, Gynecology and Obstetrics 175 243-248. (https://doi.org/10.1097/00132586-199306000-00030)

Corrêa TD, Jeger V, Pereira AJ, Takala J, Djafarzadeh S \& Jakob SM 2014 Angiotensin II in septic shock: effects on tissue perfusion, organ function, and mitochondrial respiration in a porcine model of fecal peritonitis. Critical Care Medicine 42 e550-e559. (https://doi. org/10.1097/CCM.0000000000000397)

De Backer D, Hollenberg S, Boerma C, Goedhart P, Büchele G, Ospina-Tascon G, Dobbe I \& Ince C 2007 How to evaluate the microcirculation: report of a round table conference. Critical Care $\mathbf{1 1}$ R101. (https://doi.org/10.1186/cc6118)

de Cavanagh EMV, Piotrkowski B, Basso N, Stella I, Inserra F, Ferder L \& Fraga CG 2003 Enalapril and losartan attenuate mitochondrial dysfunction in aged rats. FASEB Journal 17 1096-1098. (https://doi. org/10.1096/fj.02-0063fje)

Deitch EA, Forsythe R, Anjaria D, Livingston DH, Lu Q, Xu D-Z \& Redl H 2004 The role of lymph factors in lung injury, bone marrow suppression, and endothelial cell dysfunction in a primate model of trauma-hemorrhagic shock. Shock 22 221-228. (https://doi. org/10.1097/01.shk.0000133592.55400.83)

Dyson DH 2012 Positive pressure ventilation during anesthesia in dogs: assessment of surface area derived tidal volume. Canadian Veterinary Journal 53 63-66.

Ferrario CM \& Chappell MC 2004 Novel angiotensin peptides. Cellular and Molecular Life Sciences 61 2720-2727. (https://doi.org/10.1007/ s00018-004-4243-4)

Fournell A, Schwarte LA, Kindgen-Milles D, Müller E \& Scheeren TWL 2003 Assessment of microvascular oxygen saturation in gastric mucosa in volunteers breathing continuous positive airway pressure. Critical Care Medicine 31 1705-1710. (https://doi.org/10.1097/01. CCM.0000063281.47070.53)

Francis RCE, Höhne C, Kaczmarczyk G \& Boemke W 2004 Effect of angiotensin II and endothelin-1 receptor blockade on the haemodynamic and hormonal changes after acute blood loss and after retransfusion in conscious dogs. Acta Physiologica Scandinavica 180 319-328. (https://doi.org/10.1111/j.1365-201X.2004.01265.x)

Gunther S, Gimbrone MA \& Alexander RW 1980 Identification and characterization of the high affinity vascular angiotensin II receptor in rat mesenteric artery. Circulation Research 47 278-286. (https://doi. org/10.1161/01.RES.47.2.278)
Hiltebrand LB, Krejci V, Jakob SM, Takala J \& Sigurdsson GH 2007 Effects of vasopressin on microcirculatory blood flow in the gastrointestinal tract in anesthetized pigs in septic shock. Anesthesiology 106 1156-1167. (https://doi.org/10.1097/01.anes.0000267599.02140.86)

Hornig B, Landmesser U, Kohler C, Ahlersmann D, Spiekermann S, Christoph A, Tatge H \& Drexler H 2001 Comparative effect of ace inhibition and angiotensin II type 1 receptor antagonism on bioavailability of nitric oxide in patients with coronary artery disease: role of superoxide dismutase. Circulation 103 799-805. (https://doi. org/10.1161/01.CIR.103.6.799)

Inoue N, Kinugawa S, Suga T, Yokota T, Hirabayashi K, Kuroda S, Okita K \& Tsutsui H 2012 Angiotensin II-induced reduction in exercise capacity is associated with increased oxidative stress in skeletal muscle. American Journal of Physiology: Heart and Circulatory Physiology 302 H1202-H1210. (https://doi.org/10.1152/ajpheart.00534.2011)

Jakob SM \& Takala J 2000 Gut perfusion in the critically ill. Intensive Care Medicine 26 813-815. (https://doi.org/10.1007/s001340051253)

Konstam MA, Neaton JD, Dickstein K, Drexler H, Komajda M, Martinez FA, Riegger GAJ, Malbecq W, Smith RD, Guptha S, et al. 2009 Effects of high-dose versus low-dose losartan on clinical outcomes in patients with heart failure (HEAAL study): a randomised, double-blind trial. Lancet 374 1840-1848. (https://doi.org/10.1016/ S0140-6736(09)61913-9)

Kortbeek JB, Al Turki SA, Ali J, Antoine JA, Bouillon B, Brasel K, Brenneman F, Brink PR, Brohi K, Burris D, et al. 2008 Advanced trauma life support, 8 th edition, the evidence for change. Journal of Trauma 64 1638-1650. (https://doi.org/10.1097/ TA.0b013e3181744b03)

Krug A 2006 Mikrozirkulation und Sauerstoffversorgung des Gewebes: Methode des so genannten O2C (oxygen to see) [Microcirculation and oxygen supply of tissue: method of so-called 02C]. Phlebologie 35 300-312. (https://doi.org/10.1055/s-0037-1622158)

Kurz KD \& Zehr JE 1978 Mechanisms of enhanced renin secretion during CO2 retention in dogs. American Journal of Physiology 234 H573-H581. (https://doi.org/10.1152/ajpheart.1978.234.5.H573)

Laesser M, Fändriks L, Pettersson A, Ewert S \& Aneman A 2000 Angiotensin II blockade in existing hypovolemia: effects of candesartan in the porcine splanchnic and renal circulation. Shock $\mathbf{1 4}$ 471-477. (https://doi.org/10.1097/00024382-200014040-00009)

Laesser M, Oi Y, Ewert S, Fändriks L \& Aneman A 2004 The angiotensin II receptor blocker candesartan improves survival and mesenteric perfusion in an acute porcine endotoxin model. Acta Anaesthesiologica Scandinavica 48 198-204. (https://doi.org/10.1111/j.00015172.2004.00283.x)

Li S, Wu WC, He CY, Han Z, Jin DY \& Wang L 2008 Change of intestinal mucosa barrier function in the progress of non-alcoholic steatohepatitis in rats. World Journal of Gastroenterology 14 3254-3258. (https://doi.org/10.3748/wjg.14.3254)

Lo MW, Goldberg MR, McCrea JB, Lu H, Furtek CI \& Bjornsson TD 1995 Pharmacokinetics of losartan, an angiotensin II receptor antagonist, and its active metabolite EXP3174 in humans. Clinical Pharmacology and Therapeutics 58 641-649. (https://doi.org/10.1016/00099236(95)90020-9)

Marsilio R, D’Antiga L, Zancan L, Dussini N \& Zacchello F 1998 Simultaneous HPLC determination with light-scattering detection of lactulose and mannitol in studies of intestinal permeability in pediatrics. Clinical Chemistry 44 1685-1691.

Meissner A, Weber TP, Van Aken H \& Rolf N 1999 Limited upper thoracic epidural block and splanchnic perfusion in dogs. Anesthesia and Analgesia 89 1378-1381. (https://doi.org/10.1097/00000539199912000-00009)

Olschewski H, Ghofrani HA, Schmehl T, Winkler J, Wilkens H, Höper MM, Behr J, Kleber FX \& Seeger W 2000 Inhaled iloprost to treat severe pulmonary hypertension. An uncontrolled trial. German PPH Study Group. Annals of Internal Medicine 132 435-443. (https:// doi.org/10.7326/0003-4819-132-6-200003210-00003) https://joe.bioscientifica.com https://doi.org/10.1530/JOE-19-0030 (c) 2019 Society for Endocrinology Published by Bioscientifica Ltd. Printed in Great Britain 
Olszanecki R, Madej J, Suski M, Gebska A, Bujak-Gizycka B \& Korbut R 2009 Angiotensin metabolism in rat stomach wall: prevalence of angiotensin-(1-7) formation. Journal of Physiology and Pharmacology 60 191-196.

Pappenheimer JR \& Reiss KZ 1987 Contribution of solvent drag through intercellular junctions to absorption of nutrients by the small intestine of the rat. Journal of Membrane Biology 100 123-136. (https:// doi.org/10.1007/BF02209145)

Pawlik MW, Kwiecien S, Ptak-Belowska A, Pajdo R, Olszanecki R, Suski M, Madej J, Targosz A, Konturek SJ, Korbut R, et al. 2016 The reninangiotensin system and its vasoactive metabolite angiotensin-(1-7) in the mechanism of the healing of preexisting gastric ulcers. The involvement of Mas receptors, nitric oxide, prostaglandins and proinflammatory cytokines. Journal of Physiology and Pharmacology 67 75-91.

Price HL, Deutsch S, Marshall BE, Stephen GW, Behar MG \& Neufeld GR 1966 Hemodynamic and metabolic effects of hemorrhage in man, with particular reference to the splanchnic circulation. Circulation Research 18 469-474. (https://doi.org/10.1161/01.RES.18.5.469)

Reilly PM \& Bulkley GB 1993 Vasoactive mediators and splanchnic perfusion. Critical Care Medicine 21 S55-S68. (https://doi. org/10.1097/00003246-199302001-00011)

Sato N, Kawano S, Kamada T \& Takeda M 1986 Hemodynamics of the gastric mucosa and gastric ulceration in rats and in patients with gastric ulcer. Digestive Diseases and Sciences 31 35S-41S. (https://doi. org/10.1007/BF01309321)

Schwartges I, Picker O, Beck C, Scheeren TWL \& Schwarte LA 2010 Hypercapnic acidosis preserves gastric mucosal microvascular oxygen saturation in a canine model of hemorrhage. Shock 34 636-642. (https://doi.org/10.1097/SHK.0b013e3181e68422)

Siniscalchi A, Gamberini L, Laici C, Bardi T \& Faenza S 2015 Thoracic epidural anesthesia: effects on splanchnic circulation and implications in Anesthesia and Intensive care. World Journal of Critical Care Medicine 4 89-104. (https://doi.org/10.5492/wjccm.v4.i1.89)

Takada S, Kinugawa S, Hirabayashi K, Suga T, Yokota T, Takahashi M, Fukushima A, Homma T, Ono T, Sobirin MA, et al2013 Angiotensin II receptor blocker improves the lowered exercise capacity and impaired mitochondrial function of the skeletal muscle in type 2 diabetic mice. Journal of Applied Physiology 114 844-857. (https://doi.org/10.1152/ japplphysiol.00053.2012)

Thai H, Wollmuth J, Goldman S \& Gaballa M 2003 Angiotensin subtype 1 rReceptor (AT1) blockade improves vasorelaxation in heart failure by up-regulation of endothelial nitric-oxide synthase via activation of the AT2 receptor. Journal of Pharmacology and Experimental Therapeutics 307 1171-1178. (https://doi.org/10.1124/jpet.103.054916)

Thomas VL \& Nielsen MS 1991 Administration of angiotensin II in refractory septic shock. Critical Care Medicine 19 1084-1086. (https:// doi.org/10.1097/00003246-199108000-00020)
Truse R, Hinterberg J, Schulz J, Herminghaus A, Weber A, MettlerAltmann T, Bauer I, Picker O \& Vollmer C 2017 Effect of topical iloprost and nitroglycerin on gastric microcirculation and barrier function during hemorrhagic shock in dogs. Journal of Vascular Research 54 109-121. (https://doi.org/10.1159/ 000464262)

Umehara S, Tanaka M \& Nishikawa T 2006 Effects of sevoflurane anesthesia on carotid-cardiac baroreflex responses in humans. Anesthesia and Analgesia 102 38-44. (https://doi.org/10.1213/01. ane.0000183651.10514.9a)

Väisänen O, Parviainen I, Ruokonen E, Hippeläinen M, Berg E, Hendolin H \& Takala J 1998 Epidural analgesia with bupivacaine does not improve splanchnic tissue perfusion after aortic reconstruction surgery. British Journal of Anaesthesia 81 893-898. (https://doi. org/10.1093/bja/81.6.893)

Verdant CL, De Backer D, Bruhn A, Clausi CM, Su F, Wang Z, Rodriguez H, Pries AR \& Vincent JL 2009 Evaluation of sublingual and gut mucosal microcirculation in sepsis: a quantitative analysis. Critical Care Medicine 37 2875-2881. (https://doi.org/10.1097/ CCM.0b013e3181b029c1)

Vollmer C, Schwartges I, Behmke R, Bauer I \& Picker O 2013a Hypercapnia counteracts captopril-induced depression of gastric mucosal oxygenation. Journal of Endocrinology 218 245-253. (https:// doi.org/10.1530/JOE-13-0132)

Vollmer C, Schwartges I, Swertz M, Beck C, Bauer I \& Picker O 2013b Hypothermia improves oral and gastric mucosal microvascular oxygenation during hemorrhagic shock in dogs. Oxidative Medicine and Cellular Longevity 2013 589606. (https://doi. org/10.1155/2013/589606)

Vollmer C, Weber APM, Wallenfang M, Hoffmann T, Mettler-Altmann T, Truse R, Bauer I, Picker O \& Mathes AM 2017 Melatonin pretreatment improves gastric mucosal blood flow and maintains intestinal barrier function during hemorrhagic shock in dogs. Microcirculation $\mathbf{2 4}$ e12345. (https://doi.org/10.1111/micc.12345)

Wall P, Buising C, Henderson L, Freeman B, Vincent R, Albright J \& Paradise N 2003 Enalaprilat improves systemic and mesenteric blood flow during resuscitation from hemorrhagic shock in dogs. Shock 19 289-296. (https://doi.org/10.1097/00024382200303000-00015)

Weir MR 2007 Effects of renin-angiotensin system inhibition on end-organ protection: can we do better? Clinical Therapeutics 29 1803-1824. (https://doi.org/10.1016/j.clinthera.2007.09.019)

Yilmaz EN, Vahl AC, van Rij GL, Vink GQ, Lange-De Klerk ES, Brom HL \& Rauwerda JA 1999 The renin-angiotensin system in swine during hypovolaemic shock combined with low-flow ischaemia of the sigmoid colon. Cardiovascular Surgery 7 539-544. (https://doi. org/10.1016/S0967-2109(99)00009-5)

Received in final form 8 April 2019

Accepted 12 April 2019

Accepted Preprint published online 12 April 2019 https://joe.bioscientifica.com https://doi.org/10.1530/JOE-19-0030
(C) 2019 Society for Endocrinology Published by Bioscientifica Ltd. Printed in Great Britain 